\title{
Anabases
}

ANABASES Traditions et réceptions de l'Antiquité

$24 \mid 2016$

Varia

\section{Francesca Prescendi, Rois éphémères, enquêtes sur le sacrifice humain}

Claire Joncheray

\section{(2) OpenEdition}

1 Journals

Édition électronique

URL : http://journals.openedition.org/anabases/5787

DOI : 10.4000/anabases. 5787

ISSN : 2256-9421

Éditeur

E.R.A.S.M.E.

\section{Édition imprimée}

Date de publication : 10 novembre 2016

Pagination : 361-363

ISSN : 1774-4296

\section{Référence électronique}

Claire Joncheray, «Francesca Prescendi, Rois éphémères, enquêtes sur le sacrifice humain », Anabases [En ligne], 24 | 2016, mis en ligne le 15 novembre 2016, consulté le 24 septembre 2020. URL : http:// journals.openedition.org/anabases/5787 ; DOI : https://doi.org/10.4000/anabases.5787

Ce document a été généré automatiquement le 24 septembre 2020.

(c) Anabases 


\title{
Francesca Prescendi, Rois éphémères, enquêtes sur le sacrifice humain
}

\author{
Claire Joncheray
}

\section{RÉFÉRENCE}

Francesca Prescendi, Rois éphémères, enquêtes sur le sacrifice humain, Genève, Labor et fides, 2015, $198 \mathrm{p}$.

21 euros / isbn 978-2-8309-1500-6

1 Lors du colloque intitulé Sacrifices humains : dossiers, discours, comparaisons, paru en 2013 (compte-rendu dans Anabases 20,2014, p. 425-429), unarticledeF. Prescendi (p.231-248) abordait le problème des rois éphémères sacrifiés à la fin d'une période de fête dans les rites antiques et surtout romains, à partir du texte des Actes de Saint Dasius découvert à la fin du XIX ${ }^{e}$ s. et de leur portée historiographique. Cet article abordait les principaux thèmes que l'ouvrage paru en 2015 (Rois éphémères, enquêtes sur le sacrifice humain) reprend dans un ensemble cohérent qui suit la logique de la recherche.

2 En effet, à l'occasion d'un séminaire sur les fêtes de fin d'année dans le monde romain, l'auteure s'est penchée sur la fête des Saturnales et s'est questionnée sur le rapport entre les sacrifices humains et le dieu Saturne. Au départ de cette recherche, l'article de C. Lévi-Strauss intitulé "le Père Noël supplicié " (Les temps modernes, $n^{\circ} 77,1952$, p. 1572-1590) qui s'appuie lui-même sur un fait divers de décembre 1951 quand, à Dijon, une effigie du Père Noël a été brûlée pour critiquer l'aspect commercial de la fête de la Nativité. D'où l'idée que l'image de la mise à mort d'une figure représentant les maux des hommes en fin d'année correspondrait pour Lévi-Strauss à une réminiscence des anciens mythes associés aux boucs émissaires et à la substitution des sacrifices humains par des représentations symboliques. Un des arguments reposait sur la comparaison avec les fêtes de fin d'année à Rome, appelées Saturnales, pendant lesquelles les jeux de gladiateurs se substitueraient aux sacrifices humains, dont l'existence est prouvée par l'étude de J. G. Frazer dans son livre le Rameau d'or: ce livre traite de la mort et de la 
résurrection de celui qui incarne le pouvoir royal et regroupe toutes les sources présentant un personnage transformé en roi et mis à mort.

3 F. Prescendi entend dérouler le fil de cette argumentation. Le premier chapitre présente le fait divers de Dijon puis l'article de Lévi-Strauss. S'ensuit un rappel mythologique : Saturne est surtout un dieu agricole et ses fêtes présentent un lien avec la fin des semailles, l'espérance d'une renaissance printanière et la fertilité de la terre. À partir du III ${ }^{e}$ s. av. J.-C., Saturne s'approprie des légendes du dieu grec Cronos, qui (entre autres) dévora ses enfants, et devient un dieu ambigu entre civilisation et violence. Lors des fêtes dédiées à Saturne, il existerait bien un roi, d'après le rhéteur Lucien, mais son champ d'action est restreint au domaine privé, comme régisseur de banquet. Aucun élément ne permet d'affirmer que ce roi est mis à mort à la fin des fêtes : l'idée du sacrifice humain semble concerner alors davantage l'imaginaire que la pratique rituelle.

4 Les chapitres 2 et 3 de cet ouvrage expliquent comment est né cet imaginaire à travers l'étude de la genèse du chapitre du Rameau d'or de J. G. Frazer (1854-1941) consacré aux Saturnales publié en 1890, en lien avec la passion du Christ comme rituel de mise à mort du roi dans une seconde version en 1900 (passion du Christ qui finit en annexe lors de la troisième version en 1911). Frazer fonde sa réflexion d'un sacrifice du roi lors des Saturnales sur les Actes de Saint Dasius, unique texte qui met en rapport la fête des Saturnales avec le sacrifice du meneur de la fête déguisé en roi. Ce texte a été découvert par son contemporain F. Cumont (1868-1947). L'authenticité de ce manuscrit est assurée mais pas sa datation (postérieure à 325 mais décrivant un fait de 303) ni son auteur. Cette source décrit d'abord la fête des Saturnales puis raconte comment Dasius, soldat chrétien qui a refusé de jouer le roi lors des fêtes, est puni de mort. Le roi, tiré au sort parmi les soldats, pouvait vivre de manière exubérante pendant 30 jours avant de se tuer à la fin de la fête et s'offrir ainsi lui-même aux dieux. F. Prescendi étudie l'effervescence scientifique autour de la découverte de ce manuscrit et l'évolution de la pensée des savants Frazer, Parmentier, Cumont, Lang à partir de lettres inédites échangées entre ces savants et publiées pour la première fois dans cet ouvrage. Ces documents montrent surtout que le débat, au XIX ${ }^{\mathrm{e}}$ s., se concentre sur l'existence ou non du sacrifice humain dans la religion romaine.

5 Le chapitre 4 reprend les sources antiques citées par ces savants, selon une présentation succincte voulue par l'auteure qui pense que leur étude devrait donner lieu à une thèse. La liste des sources est indexée à la fin du livre. Il s'agit de la fête des Sacées, rite de transgression et d'inversion avec la présence d'un roi éphémère mais sans mise à mort; du rite du bouc-émissaire à Rhodes en rapport avec la divinité Artémis; du rite des Albanoi lié à la Lune et le meurtre d'un esclave sacré dont le cadavre est conservé comme une relique; de l'histoire du pauvre de Marseille qui, bien nourri, prend sur lui la misère de la ville avant sa mise à mort; des rites de devotio durant lesquels on donne sa vie pour en sauver une autre; des rites de libations de sang humain ; enfin des textes qui mettent en relation le mois de décembre et la mort des gladiateurs. L'auteure interprète ces textes selon une thématique agraire et dans le cadre de la fertilité de la terre, suivant en partie seulement les recherches de M. Le Glay. Par exemple, le sang du gladiateur devient source de force et de fécondité. Aucune de ces sources ne met en rapport direct la mise à mort d'un homme et les Saturnales : F. Precendi montre ainsi comment la pratique décrite dans le martyre de Saint Dasius n'a 
pas de comparaison à Rome. Les sacrifices humains sont donc étrangers aux fêtes des Saturnales.

6 Cette conclusion convaincante est bien amenée dans un texte de lecture facile qui suit la logique de la réflexion scientifique. Malgré quelques présentations paraphrasées des lettres au chapitre 3 et des citations iconographiques en provenance de sites Internet non libres de droit, le livre de F. Prescendi est bien documenté, à partir de sources inédites. Le déroulement intellectuel apporte beaucoup de fraîcheur : il est plaisant de jouer entre les textes antiques et l'historiographie actuelle. Le mois de décembre s'avère correspondre tout à fait aux mois des excès et être le moment propice à la transgression.

\section{AUTEURS}

\section{CLAIRE JONCHERAY}

Equipe ESPRI, UMR 7045 ArScAn

claire.joncheray@free.fr 